\title{
Ischaemic heart disease: trends in mortality in Hong Kong, 1970-89
}

\author{
TS Yu, SL Wong, OL Lloyd, TW Wong
}

\begin{abstract}
Study objective-To describe the time trends for ischaemic heart disease (IHD) mortality in Hong Kong between 1970 and 1989, and to examine these trends in relation to the risk factors for IHD.

Design - A descriptive epidemiological study of time trends using mortality and population data from the Hong Kong Census and Statistics Department. Direct standardisation using the world population was made to adjust for the changing age structure. Log-linear analyses for trends were performed for the whole period and separately for 1970-79 and 1980-89. The cohort effect was studied by regrouping the data into five year groups according to the year of birth. The influences of risk factors, including hypertension, diet, and smoking, on the time trends of IHD were explored. The role of improved hospital treatment of myocardial infarction on the trends of mortality from categories of IHD was also
\end{abstract} examined.

Setting - The total Hong Kong population, 1970-89.

Main results - The substantial and steady decline of IHD mortality seen in most western countries in the past two decades was not observed in Hong Kong, which showed a plateau or slowly decreasing trend only in the past decade for both women and men. The decreasing trends were more apparent in the younger age groups, especially for women. Cohort analysis showed no significant cohort effect in men, but women born more recently had a lower mortality. Trends of risk factors did not show any close relationship with the mortality trends of IHD, except that a decrease in cigarette smoking might have contributed to the slight decrease in IHD mortality in recent years. Better detection and wider availability of treatment for hypertension might also have contributed to the decrease in IHD mortality.

Conclusion-Hong Kong started to show a slow decline in IHD mortality during the 1980 s, about one to two decades later than in other western countries and with the decreasing trend less pronounced. The reasons for this decline are not clear. More detailed information from systematic, population based surveys on life style and risk factors for IHD among the general population are needed.

(f Epidemiol Community Health 1995;49:16-21)
Heart diseases have become the second leading cause of mortality in Hong Kong during the past 20 years; ${ }^{1}$ within this group of diseases, ischaemic heart disease (IHD) is the major category. This changing pattern of proportionate mortality, mentioned by Colbourne ${ }^{23}$ and Kleevens, ${ }^{4}$ might be a sign of Hong Kong's entry into an economic stage of prosperity and affluence. In most affluent western countries, IHD emerged as a major cause of death in the first half of the 20th century, as a result of a decrease in mortality from infectious diseases coupled with an increase in the age specific mortality of IHD. The same mechanisms may be operating in the circumstances of Hong Kong, especially during the 1970s.

Canada, ${ }^{5}$ Australia, and the United States ${ }^{6}$ started to experience a reverse in the increasing trends of IHD mortality in the late 1960s. A similar decrease in IHD mortality was also experienced by other developed countries in the mid or late $1970 \mathrm{~s},{ }^{7-11}$ whereas many of the eastern European countries experienced an increase in IHD mortality during the $1970 \mathrm{~s}^{1213}$ The decline in trends was attributed both to a reduction in coronary risk factors in the populations $s^{6-71014}$ and also to improved survival as a result of advances in medical treatment. ${ }^{10111415}$

In earlier studies of the trends in cardiovascular diseases mortality in Hong Kong, heart diseases (including hypertension) were grouped as one entity, making it impossible to elucidate individual patterns of IHD. ${ }^{34}$ In another study which reported an increase in mortality from IHD during the decade $1969-78,{ }^{16}$ no age adjustment was made.

In 1970, Hong Kong had one of the lowest IHD mortality rates, with rates of 34 and 12 per 100000 population respectively for men and women. ${ }^{17}$ With the Territory's rapid economic development and westernisation, heart diseases became a leading cause of death. The associations reported between socioeconomic status and IHD mortality were consistent with the impact of affluence noted elsewhere. A study of geographical and socioeconomic variation in IHD mortality among men in Hong Kong showed a high correlation between the standardised mortality ratios (SMRs) and the proportions of professional, administrative and managerial workers in different geographical districts. ${ }^{18}$ A more recent study confirmed the positive association of high socioeconomic status with IHD mortality by combining several indicators of status into a factor score. ${ }^{19}$ These results for Hong Kong thus differed from those in western countries over the past 20 to 30 
years where IHD mortality has usually been higher in the lower social classes. ${ }^{20-22}$

The aims of this study were to examine the time trends for IHD mortality in Hong Kong over 20 years between 1970 and 1989, to determine if there has been any decline in the IHD mortality similar to the declines experienced by most of the developed countries, to compare the trends for IHD in Hong Kong with the trends for cerebrovascular disease and hypertension, and to examine the relationship with secular trends of risk factors for IHD for which data were available.

\section{Methods}

Mortality data were obtained from the Hong Kong Census and Statistics Department. The coding for the underlying cause of death was based on the 8th and 9th revisions of the International Classification of Diseases: ICD 8 (1965) before 1976 and ICD 9 (1975) since 1976. IHD included all deaths coded 410-414 in both editions. Since only the broad category of IHD was studied, the change over from ICD 8 to ICD 9 should not introduce any artefact in the trends.

The reliability of studies of causes of death depends on the accuracy of death certification. In Hong Kong, because of urbanisation and the close proximity of communities to hospitals, $80 \%$ of all deaths (from all causes) occurred in hospitals and $99.9 \%$ of death certificates were signed by medical practitioners. ${ }^{19}$ Population data were obtained from the censuses of 1971 and 1981, and from the bi-censuses (a small census with a sampling fraction of one in seven) of 1976 and 1986. Mid year populations for the intervening years were estimated, with additional data on births, deaths, and immigration obtained from the Registrar of Births and Deaths and from the Immigration Department. For comparing the all-ages mortality in different years, the 1960 world population $^{23}$ was used for standardisation using 5 year age groups and including all ages.

Log-linear analyses for trends were performed for the whole period of 1970-89 and separately for 1970-79 and 1980-89. Age and sex specific annual percentage changes (APC) were calculated. ${ }^{24}$ The possibility of any cohort effect was analysed by regrouping the data into five year groups according to the year of birth.

Data on the prevalences and secular trends of the following coronary risk ractors: hypertension, hypercholesterolaemia, diabetes mellitus, smoking, physical inactivity, and obesity were not available, and hence proxy parameters were used. Mortality data from hypertensive diseases (ICD 401-405) and cerebrovascular diseases (ICD 430-438) for the same period were analysed. Dietary changes were estimated from local per capita consumption figures obtained from the Department of Agriculture and Fisheries (fresh food items) or calculated from the import and re-export figures from government trade statistics. Prevalences of smoking among the general population in the more recent years were obtainable from the social data collected by the
General Household Survey (1982, 1983, 1984, 1986, 1988, 1990) conducted by the Census and Statistics Department. ${ }^{25} 26$ A UNESCO study in Hong Kong in the early 1970s also provided data on the prevalence of smoking in 1974. ${ }^{27}$

To assess the role of improved hospital treatment of myocardial infarction on the trends of mortality from IHD, case fatality rates during the period of study would be very helpful. Unfortunately, the information available was inadequate for calculating these rates. Comparisons were made between the numbers of patients admitted to all hospitals in Hong Kong with diagnoses of acute myocardial infarction (ICD 410) and other IHD (ICD 411-414) obtained from hospital statistics for the years $1980-89^{28}$ and the total numbers of deaths in Hong Kong as a result of the above causes during the same period.

\section{Results}

The secular trends of IHD mortality in Hong Kong showed an increase for both sexes during most of the $1970 \mathrm{~s}$, reached a plateau in the late $1970 \mathrm{~s}$, and thereafter declined gradually during the 1980 s (fig 1 , with mortality rates plotted semilogarithmically against the year of death). Men had higher mortality throughout this period.

The age and sex specific death rates from IHD increased with increasing age (fig 2 , again plotted semilogarithmically). Men showed a higher mortality than women in all age groups, but the differences were more noticeable in younger (about three to four times) than in older (about twice) age groups.

The log-linear regression analyses of the trends for the whole period 1970-89 showed no clear trend for IHD mortality (all ages) in the men but a slight increasing trend in the women (table 1). However, when this period was divided into two 10 year periods - that is, 1970-79 and 1980-89-significant upward

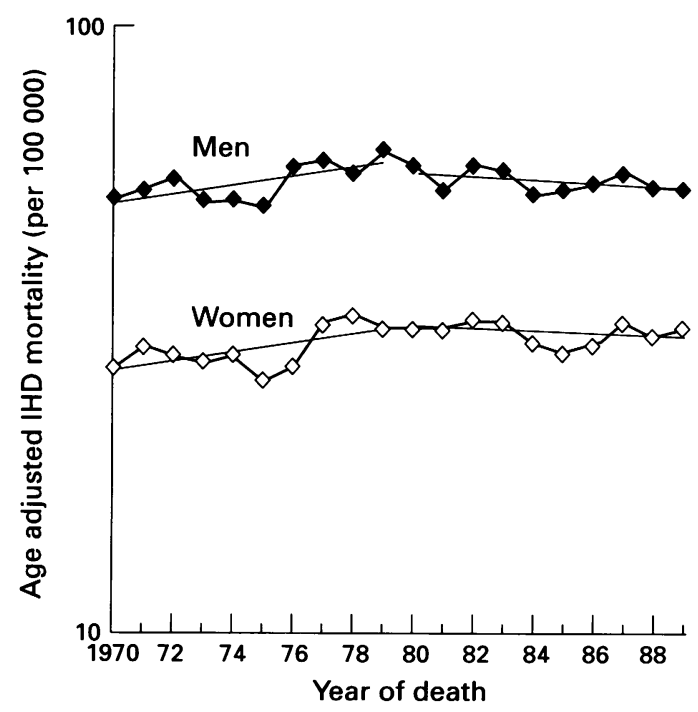

Figure 1 Age adjusted ischaemic heart disease mortality (on log scale) in men and women in Hong Kong by year of death, 1970-89. (The log-linear regressions for the trends in the two decades are shown in bold solid lines.) 


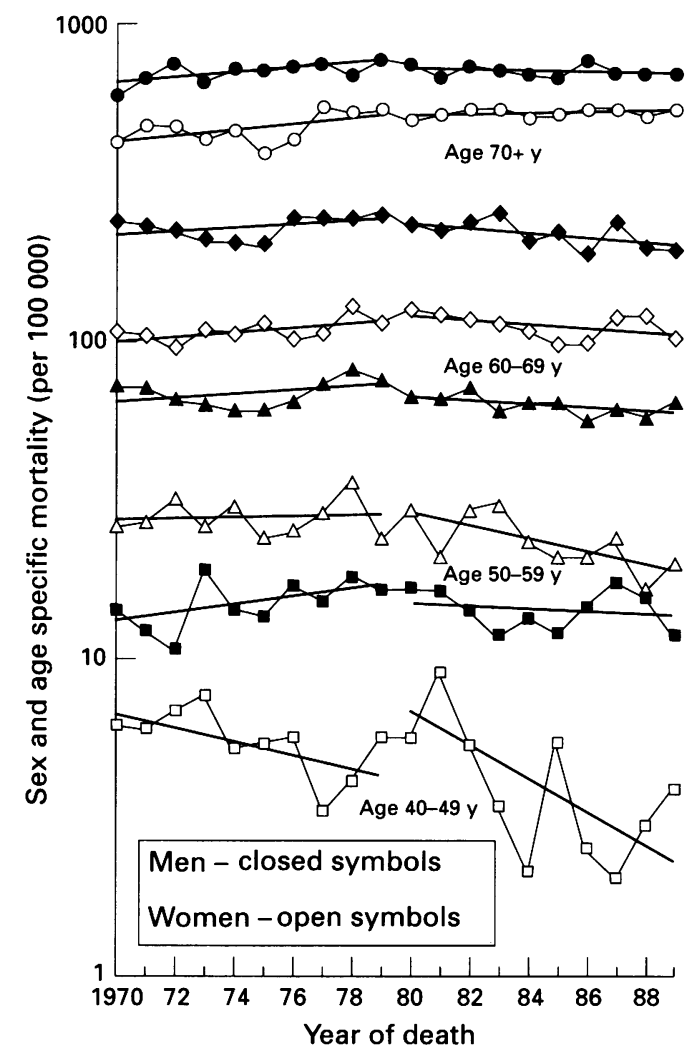

Figure 2 Sex and age specific ischaemic heart disease mortality (on log scale) in Hong Kong by year of death, 1970-89. (The log-linear regressions for the trends in the two decades are shown in bold solid lines.)

slopes emerged for both men and women (all ages) in the first decade (fig 1, table 1): male rates for all ages increased by an average of $1.7 \%$ each year while the annual increase in

Estimates in log-linear regression analysis for trends of ischaemic heart disease mortality in Hong Kong

\begin{tabular}{|c|c|c|c|c|c|c|}
\hline \multirow[t]{2}{*}{ Estimator } & \multicolumn{3}{|l|}{ Men } & \multicolumn{3}{|l|}{ Women } \\
\hline & $1970-79$ & $1980-89$ & $1970-89$ & $1970-79$ & $1980-89$ & $1970-89$ \\
\hline $\begin{array}{l}\text { All ages: } \\
\text { A } \\
\text { B } \\
\mathbf{R}^{2} \\
\text { APC }(\%) \dagger\end{array}$ & $\begin{array}{l}3.9231 \\
0.0174^{*} \\
0.4744^{*} \\
1 \cdot 7\end{array}$ & $\begin{array}{c}4 \cdot 1184 \\
-0.0056 \\
0.1590 \\
-0.5\end{array}$ & $\begin{array}{l}4 \cdot 0022 \\
0 \cdot 0023 \\
0 \cdot 052 \\
0 \cdot 2\end{array}$ & $\begin{array}{l}3.2889 \\
0.0186^{*} \\
0.4026^{*} \\
1.9\end{array}$ & $\begin{array}{c}3.5157 \\
-0.0034 \\
0.0675 \\
-0.3\end{array}$ & $\begin{array}{l}3 \cdot 3548 \\
0.0070^{*} \\
0.3207^{*} \\
0 \cdot 7\end{array}$ \\
\hline $\begin{array}{l}\text { Aged } 40-49: \\
\text { A } \\
\text { B } \\
\mathrm{R}^{2} \\
\text { APC }(\%)\end{array}$ & $\begin{array}{l}2 \cdot 5522 \\
0 \cdot 0315 \\
0 \cdot 2852 \\
3 \cdot 2\end{array}$ & $\begin{array}{c}2.8372 \\
-0.0087 \\
0.0312 \\
-0.86\end{array}$ & & $\begin{array}{c}1.9567 \\
-0.0419 \\
0.3338 \\
-4 \cdot 1\end{array}$ & $\begin{array}{c}3.2543 \\
-0.1181^{*} \\
0.4373^{*} \\
-11.13\end{array}$ & \\
\hline $\begin{array}{l}\text { Aged 50-59: } \\
\text { A } \\
\text { B } \\
\text { R }^{2} \\
\text { APC }(\%)\end{array}$ & $\begin{array}{l}4 \cdot 1646 \\
0 \cdot 0162 \\
0 \cdot 1992 \\
1 \cdot 64\end{array}$ & $\begin{array}{c}4.3679 \\
-0.0114 \\
0.2688 \\
-1.12\end{array}$ & & $\begin{array}{l}3 \cdot 3063 \\
0 \cdot 0074 \\
0 \cdot 0229 \\
0 \cdot 74\end{array}$ & $\begin{array}{c}3.8742 \\
-0.0437^{*} \\
0.4280^{*} \\
-4.27\end{array}$ & \\
\hline $\begin{array}{l}\text { Aged 60-69: } \\
\text { A } \\
\text { B } \\
\mathrm{R}^{2} \\
\text { APC(\%) }\end{array}$ & $\begin{array}{l}5 \cdot 3622 \\
0.0160 \\
0.2594 \\
1.61\end{array}$ & $\begin{array}{c}5.6699 \\
-0.0157 \\
0.2359 \\
-1.56\end{array}$ & & $\begin{array}{l}4 \cdot 6010 \\
0 \cdot 0185 \\
0 \cdot 3823 \\
1 \cdot 87\end{array}$ & $\begin{array}{c}4.9524 \\
-0.0120 \\
0.1647 \\
-1.19\end{array}$ & \\
\hline $\begin{array}{l}\text { Aged } 70-79: \\
\text { A } \\
\text { B } \\
\text { R }^{2} \\
\text { APC }(\%)\end{array}$ & $\begin{array}{l}6.4746 \\
0.0184^{*} \\
0.4502^{*} \\
1.85\end{array}$ & $\begin{array}{l}6.5762 \\
0.0024 \\
0.0288 \\
0.24\end{array}$ & & $\begin{array}{l}6 \cdot 0327 \\
0 \cdot 0243 \\
0 \cdot 3862 \\
2 \cdot 4\end{array}$ & $\begin{array}{l}6 \cdot 1218 \\
0 \cdot 0127^{*} \\
0.5924^{*} \\
1 \cdot 28\end{array}$ & \\
\hline
\end{tabular}

$* \mathrm{p}<0.05$

t $\mathrm{APC}(\%)=$ annual percentage change female rates was $1.9 \%$. During the second decade, by contrast, decreasing trends were seen for both sexes, though the downward slopes for both men and women were not significant. The average annual decrease was $0.5 \%$ in men and $0.3 \%$ in women.

When the mortality trends of individual age groups were similarly analysed (table 1, fig 2), all except one group (women aged 40-49) showed an increase in the first decade, with the rate of men aged 70-79 achieving statistical significance. During the second decade, by contrast, all except two groups (men and women aged 70-79) showed decreasing trends and those trends for women aged 40-49 and 50-59 were significant.

When birth cohort effects were investigated by plotting the mortality of different age groups, again semilogarithmically, aginst the year of birth $^{29}$ (figs 3 and 4), no clear cohort effect was observed among the men. However, women born between 1925 and after had experienced a steady decline in mortality.

Data for hypertensive diseases (ICD 401405) and cerebrovascular diseases (ICD 430438) for the same period showed a decrease in mortality from both conditions in both sexes. The decrease in cerebrovascular diseases occurred at about the same time that IHD mortality began to decrease, but the rate of the decrease of the former was much more rapid and persistent. The decrease of hypertensive diseases preceded that for cerebrovascular diseases by about eight to nine years.

The per capita consumptions of various food items showed continuously increasing trends for dairy products, eggs, meat and fruits and vegetables, but decreasing trends for fish and cereals. The prevalence of daily smokers in the population dropped steadily for both men and women from 1974-90, the proportionate rate of decrease was greater in the females (measured by the slope of the points on the log

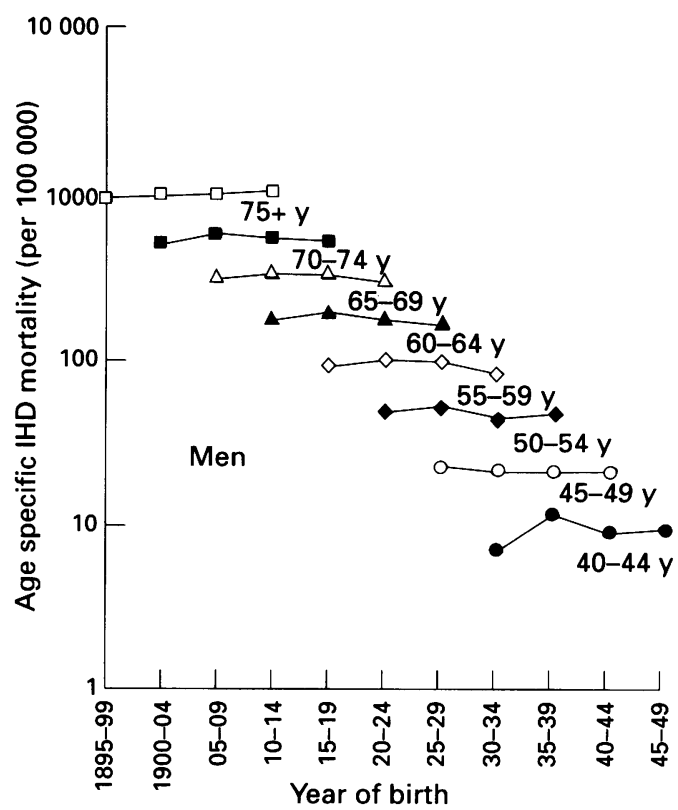

Figure 3 Age specific ischaemic heart disease mortality in men in Hong Kong by year of birth, 1895-99 to 1945-49. 


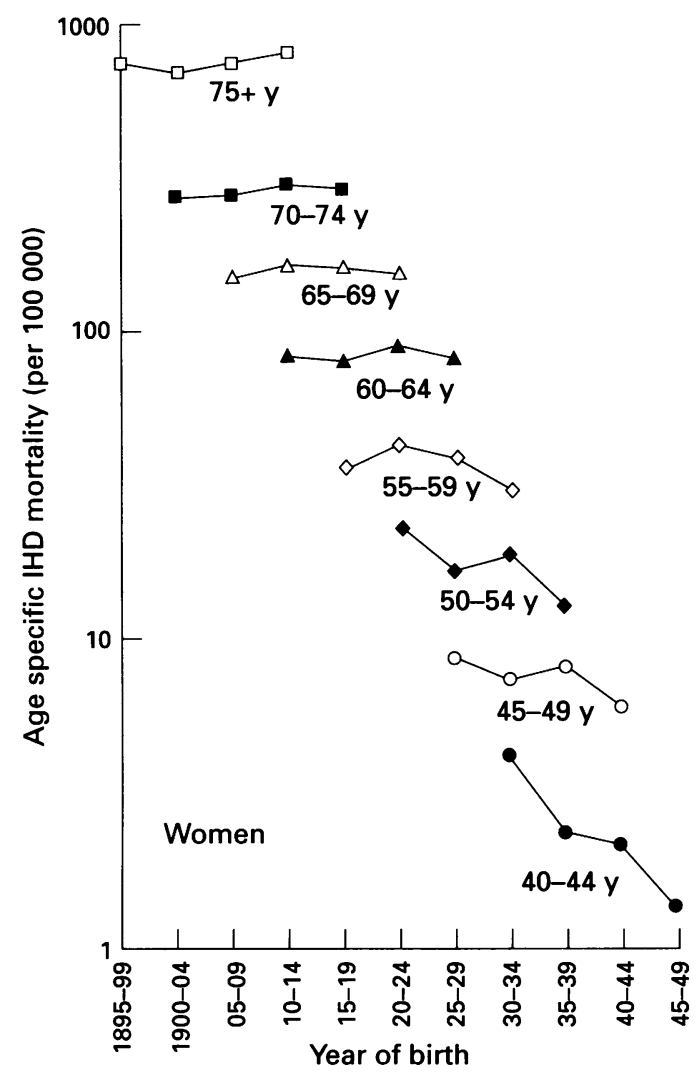

Figure 4 Age-specific ischaemic heart disease mortality in women in Hong Kong by year of birth, 1895-99 to 1945-49.

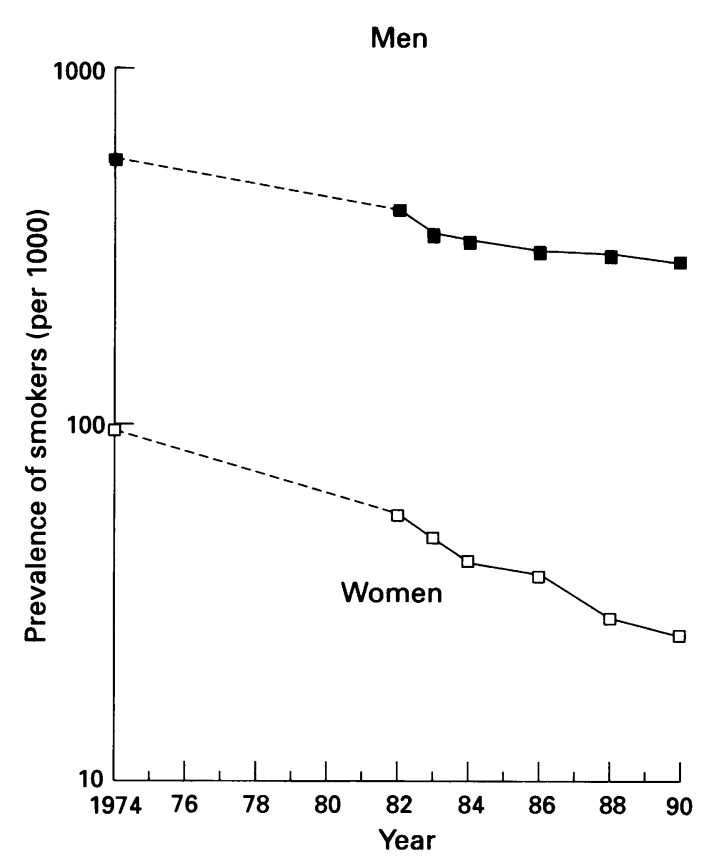

Figure 5 Prevalence of daily smokers in men and women (all ages) in Hong Kong, 1974-90.

scale)(fig 5). A breakdown of the prevalences of daily smokers in different age groups of men showed continuous decreasing trends except for the two youngest groups (15-19 and 20-29) which fluctuated in recent years. For women, only the older age groups $(40-49,50-59$, and $60+$ ) showed decreasing prevalences, whereas the three younger groups $(15-19,20-29$ and 30-39) all showed clear, increasing trends.

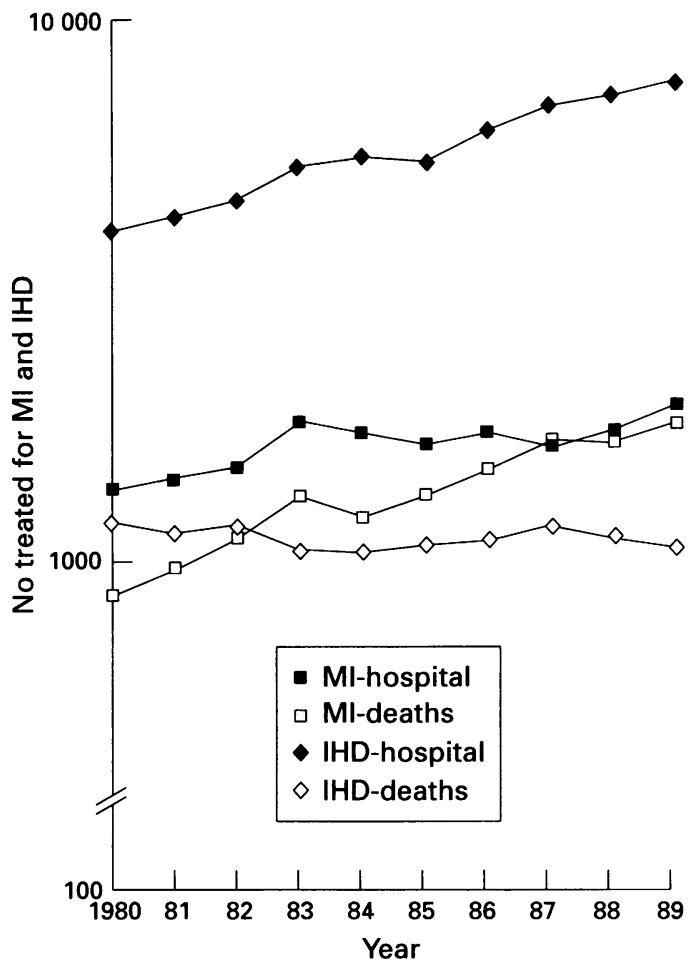

Figure 6 Numbers of inpatients treated (including deaths) in all hospitals and total numbers of deaths from acute myocardial infarction (MI) and other ischaemic heart disease (IHD) for the period 1980-89.

Admission data obtained from all hospitals for the period 1980-89 (fig 6, plotted on a semilogarithmic scale) showed that there had been a steady increase in the number of patients admitted because of acute myocardial infarction (ICD 410), but that the overall numbers of deaths from acute myocardial infarction had been increasing at an even higher rate. For other forms of IHD (ICD 411-414), the numbers of deaths had been relatively stable but the numbers of hospital admissions had been increasing throughout the period.

\section{Discussion}

While mortality from IHD has declined in most western countries, it has been increasing in many developing countries concurrently with economic development. Hong Kong is one of the most developed areas in Asia, and an assessment of the IHD mortality might provide an insight into the future trends of IHD mortality in other developing countries within the region.

The sex and age distribution of IHD mortality followed the general pattern in other countries-men and older groups were more affected. The sex difference was also less pronounced in the older groups, possibly because of the loss of the protective effects of the female sex hormones after the menopause.

The secular trend for the period as a whole was not unidirectional. There was an increasing trend in the earlier 1970s (which had continued from the 1960s) which changed to a plateau in the late 1970 s. In the early 1980 s, a decreasing trend started to emerge. 
The analysis of the trends for individual age groups showed that the rates of those over 70 years did not share the decline seen during the $1980 \mathrm{~s}$. By contrast, significantly decreasing trends were observed during this later decade in younger groups of women, with annual percentage changes of $11 \cdot 1 \%$ and $4.3 \%$ for those aged 40-49 and 50-59 respectively. However, decreasing trends among the men were not evident, so that the trends for the younger age groups (40-49 and 50-59) were no better than those for the 60-69 age group. These sex differences were confirmed in the cohort analysis: the more recent birth cohorts of women showed a progressively decreasing mortality from IHD whereas no birth cohort effect was detected in men. This discrepancy between the sexes was unexpected because in many other countries a decreasing trend in IHD mortality is usually seen first in men. This finding in Hong Kong therefore raises some concern regarding future trends of IHD mortality in men.

Population-based information on the prevalence and secular trends of coronary risk factors for IHD in Hong Kong are limited, and this lack of data prevented detailed analyses of their influence on the observed difference in trends of IHD mortality by sex. Different rates of smoking between the two sexes could have contributed to the discrepancy, because the prevalence of smoking in women in Hong Kong has been much lower than in men, especially for the more recent generations of middle and old age groups. ${ }^{2526}$ Another plausible explanation of these findings is that the younger women might have been more influenced by health education or fashion programmes, their concerns about appearance leading them to adopt healthier diets with less fat content and also to take more physical exercise. Although obesity, by itself, is not a strong contributing factor to IHD mortality, dietary modification associated with slimming can reduce other risk factors such as physical inactivity and excessive intakes of saturated fatty acids and cholesterol. No detailed data were available on physical activity levels of the population and their changes over time. In general, traditional physically demanding manual work in the production sector has been declining, with more people becoming involved in white collar, sedentary jobs. ${ }^{30}$ On the other hand, sports and fitness training have become more popular and the facilities more available in the recent years as a result of promotion by the government as well as by non-governmental agencies. Surveys are clearly needed to assess the changes in these risk factors in the two sexes.

Information from trade statistics provided some illustration of recent changes in lifestyle in Hong Kong. The figures on gross consumption of different categories of food items showed that per capita consumptions of fish and cereals have been decreasing whereas those of meat, dairy products and eggs have been continuously increasing. Thus, with the rapidly increasing economic development and westernisation in Hong Kong since the 1960s, the traditional and "healthier" Chinese diet has given way to the "less healthy" western diet.
Nevertheless, while these trends might explain the increase in IHD mortality observed in the 1970 s, they cannot explain why there has been a decrease since early 1980 s.

Cigarette consumption in the population fluctuated throughout the years, but a more stable decreasing trend was observed between 1978 and 1986. This change preceded the decrease in IHD mortality observed in men in the $1980 \mathrm{~s}$. If the decline in cigarette consumption had contributed substantially to the decline in the IHD mortality, the IHD mortality should rise again in the near future because of increasing cigarette consumption after 1986. Data on the prevalence of daily smokers collected in the last decade showed a continuous decrease in the middle and older age groups, which might have contributed to the decreasing trends of IHD. Unfortunately, similar data were incomplete for the earlier periods so that the influence of the prevalence of daily smokers could not be adequately assessed. The increasing prevalence of smokers among the younger age groups in the more recent years should raise some concern about its impact on IHD mortality in the future.

While the decrease in mortality from hypertensive disease did not necessarily indicate a decrease in the prevalence of hypertension in the population, it was at least consistent with a more effective control of the disease in the more recent decades. Cerebrovascular diseases share some of the common risk factors with IHD, and a decrease in the mortality from the former might also indicate a decrease in the associated risk factors, although better medical treatment could also explain the decrease. Thus, although no data were available specifically on the prevalences and trends of hypertension and diabetes mellitus in the general population, earlier detection and better treatment of these diseases in the recent years, as a result of better awareness and the wider availability of affordable medical treatment, might have contributed to the decrease of IHD mortality.

Data obtained from the hospitals did not support the hypothesis that advances in the treatment of acute myocardial infarction might have contributed to the decrease in mortality even if the incidence of myocardial infarction remained constant or increased because the higher number of admissions was not accompanied by a decrease in the number of deaths. With better and more widespread awareness of the symptoms of a heart attack and the improvements in transport within the territory in recent years, it would be logical to assume that a higher proportion of patients with heart attacks would be admitted into hospitals for treatment, although the true figures are not available. The better availability of coronary or intensive care units and the advanced medical interventions for patients with acute myocardial infarction should have brought about a decrease in the number of deaths relative to the number of hospital admissions. However, this decrease was not observed. For other IHDs, however, recent advances in secondary and tertiary prevention 
might have been important in reducing mortality.

In conclusion, Hong Kong began to show a slow decline in mortality from IHD during the 1980 s, about one to two decades later than similar events in other western countries and with the decreasing trend less pronounced. The reasons for this decline are not clear, but may include factors such as changing awareness and life styles among the younger generations, better management of predisposing medical conditions and more effective secondary and tertiary prevention. Hong Kong now also seems to be at the cross roads of the epidemiological transition in the relationship between socioeconomic class and IHD mortality previously observed in western countries; although the higher social classes have been more affected by IHD for some decades, this association has become weaker in recent years. If this trend should continue, the present relationship would reverse, with lower social classes showing a higher IHD mortality in the next decade. Data on lifestyle and coronary risk factors in the general population should be obtained through systematic, repeated surveys and would help to predict future trends.

1 Department of Health Annual Report-1989/1990 Hong Kong: Hong Kong Government. 1990.

2 Colbourne MJ. The pattern of disease in Hong Kong. fournal of the Hong Kong Society of Community Medicine. 1976;7:7-26.

3 Colbourne MJ. Mortality trends in Hong Kong. Fournal of the Hong Kong Society of Community Medicine. 1976;8: $18-42$.

4 Kleevens JWL. Cardiovascular diseases in Hong Kong. fournal of the Hong Kong Society of Community Medicine. 1982;13:25-36.

5 Guibert R. Could the coronary heart disease mortality rates decline be artifactual? Can $\mathcal{f}$ Public Health 1991;82(1): 43-5.

6 Dwyer T, Hetzel BS. A comparison of trends of coronary heart disease mortality in Australia, USA and England and Wales with reference to three major risk factors - hypertension, cigarette smoking and diet. Int $\mathcal{f}$ Epidemiol 1980;9(1):65-71.

7 Wilhelmsen L, Johansson S, Ulvenstam G, Welin L, Rosengren A, et al. CHD in Sweden: mortality, incidence and risk factors over 20 years in Sweden. Int $f$ Epidemiol 1989;18 (suppl 1):S101-8.

8 Tuomilehto J, Puska P, Korhonen H, Mustaniemi H, Vartiainen $\mathrm{E}$, et al. Trends and determinants of ischaemic tiainen $\mathrm{E}$, et al. Trends and determinants of ischaemic to a possible levelling off in the early 1980 s. Int $\mathcal{F}$ Epidemiol 1989;18(suppl 1):S109-17.

9 Greiser E, Joeckel KH, Giersiepen K, MaschewskySchneider U, Zachcial M. Cardiovascular disease ris factors, CHD morbidity and mortality in the Federal Republic of Germany. Int $\mathcal{F}$ Epidemiol 1989;18(suppl 1): S118-24.

10 Menotti A. Trends in CHD in Italy. Int $f$ Epidemiol 1989; 18(suppl 1):S125-8.

11 Hatano S, Changing coronary heart disease mortality and its causes in Japan during 1955-1985. Int $f$ Epidemiol 1989;18(suppl 1):S149-58.

12 Rywik S, Kupsc W. Coronary heart disease mortality trends and related factors in Poland. Cardiology 1985;72:81-7.

13 Deev AD, Oganov RG. Trends and determinants of cardiovascular mortality in the Soviet Union. Int $\mathcal{F}$ Epidemiol 1989;18(suppl 1):S137-44.

14 Beaglehole R, Dobson A, Hobbs MST, Jackson R, Martin CA. Coronary heart disease in Australia and New Zealand. Int $f$ Epidemiol 1989;18(suppl 1)S:145-48.

15 Burke GL, Sprafka JM, Folson AR, Luepker RV, Norsted SW, Blackburn H. Trends in CHD mortality, morbidity and risk factor levels from 1960 to 1986 : the Minnesota heart survey. Int 7 Epidemiol 1989;18(suppl 1).S73-81.

16 Woo KS. Epidemiology of ischaemic heart disease and coronary risk factors in Hong Kong. fournal of the Hong Kong Medical Association 1984;36:73-82.

17 Mann II, Marmot MG. Epidemiology of ischaemic heart disease. In: Weatherall DJ, Ledingham JGG, Warrell DA, eds. Oxford textbook of medicine. Oxford: Oxford University eds. Oxford textbook of med

18 Lam YM, Lau EMC, Donnan SPB. Geographic and socioeconomic variations in ischaemic heart disease in men in Hong Kong. Ann Acad Med Singapore 1984;13:211-215.

19 Wong SL, Donnan SPB. Influence of socioeconomic status on cardiovascular diseases in Hong Kong. $\mathcal{F}$ Epidemio Community Health 1992;46:148-50.

20 Marmot MG, Adelstein AM, Robinson N, Rose GA. Chaning social class distribution of heart disease. $B M \mathcal{F} 1978$ ii: $1109-12$.

21 Higgins $M$, Thomas $T$. Trends in CHD in the United States. Int f Epidemiol 1989;18(suppl 1):S58-66.

22 Helmert U, Herman B, Joeckel KH, Greiser E, Madans J. Social class and risk factors for coronary heart disease in the Federal Republic of Germany. Results of the baseline survey of the German Cardiovascular Prevention Study survey of the German Cardiovascular Prevention Study

23 IARC. Cancer Incidence in Five Continents. Vol VI. Lyon International Agency for Research on Cancer, 1992. IARC Scientific Publications No 120 .

24 Dinse GE, Hoel DG. Exploring time trends in cancer incidence. Cancer Causes and Control 1992;3:409-17.

25 Census and Statistics Department. Social data collected by the general household survey-special topics report No. V Hong Kong: Hong Kong Government, 1989.

26 Census and Statistics Department. Social data collected by the general household survey-special topics report No. VII Hong Kong: Hong Kong Government, 1991.

27 Millar S. The biosocial survey in Hong Kong. Geneva: UNESCO/UNEP, 1979:359-376.

28 Director of Medical and Health Services. Departmental Reports (1980/81 to 1989/90): Hong Kong: Hong Kong Government $1981-90$.

29 Hughes $K$. Trends in mortality from ischaemic heart disease in Singapore, 1958 to 1983. Int $\mathcal{f}$ Epidemiol 1986;15: in Sing

30 Commissioner for Labour. Annual departmental reports (1979 to 1989). Hong Kong: Hong Kong Government, 1980-90.

jech93-025 